\title{
Un Filósofo en la Real Academia de San Carlos -Entrevista al Prof. Román de la Calle-
}

José Ricardo SEGUÍ. Escritor y Periodista

"A veces he tenido la triste sensación de que --entre nosotros-- política y cultura se transformaban en dos trenes muy diferentes, que -aunque discurriendo por carriles paralelos-- viajaban efectivamente siguiendo sentidos, intereses y objetivos distintos. Sin diálogo, solo con gestos".

R. C.

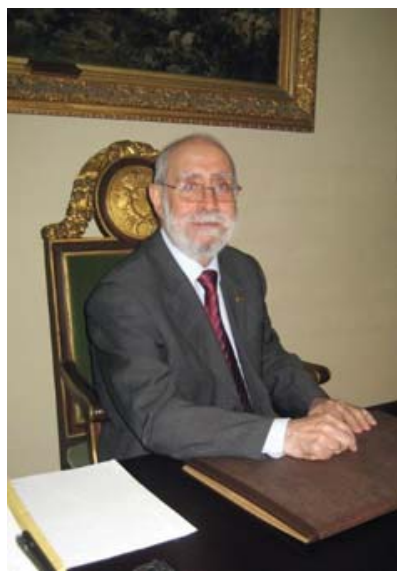

Durante dos mandatos, esto es, ocho años, el Catedrático de Estética de la Universitat de València-Estudi General ha estado al frente de la Real Academia de Bellas Artes de San Carlos, una institución con más de dos siglos de historia y garante básico de nuestro patrimonio. Román de la Calle analiza en esta conversación su paso por la institución, el trabajo desarrollado durante su presidencia así como la situación actual del universo cultural valenciano y los retos que, frente a sí, tiene el organismo, en el futuro más inmediato.

\section{¿Podría realizar una aproximación situacional a lo que han sido sus responsabilidades académicas y profesionales en San Carlos?}

Mi relación con la Real Academia de Bellas de San Carlos se inicia cuando, en el año 1998, soy elegido, por votación, miembro numerario de la histórica Institución. Bien es cierto que, desde hacía años, colaboraba periódicamente a través de mis investigaciones, convertidas en artículos, para la revista académica Archivo de Arte Valenciano. Fue, por tanto --dicho resumidamente-- el camino de la investigación 
sobre las artes en el contexto valenciano y la palanca de la Educación Artística, lo que más me acercó a la vida de la Real Academia. Cuando a finales de los años noventa, fui propuesto para académico de número y elegido por los miembros del claustro de la corporación, en mi calidad de Catedrático de Estética y Teoría de las Artes de la Universidad de Valencia y como Director del Instituto Universitario de Creatividad e Innovaciones Educativas de la misma, no pude, por mis acumuladas tareas, tomar efectiva e inmediata posesión del escaño académico --con la lectura del preceptivo discurso de ingreso, como exigen los Estatutos-- hasta dos años después, en 20 de junio del 2000. Es así como, ya a partir de esa fecha, se normalizan mis participaciones en el marco de la entidad y sobre todo se incrementan exponencialmente mis colaboraciones cuando, en el año 2004, el Presidente J. Michavila me propone entrar a formar parte de su candidatura, como Vicepresidente.

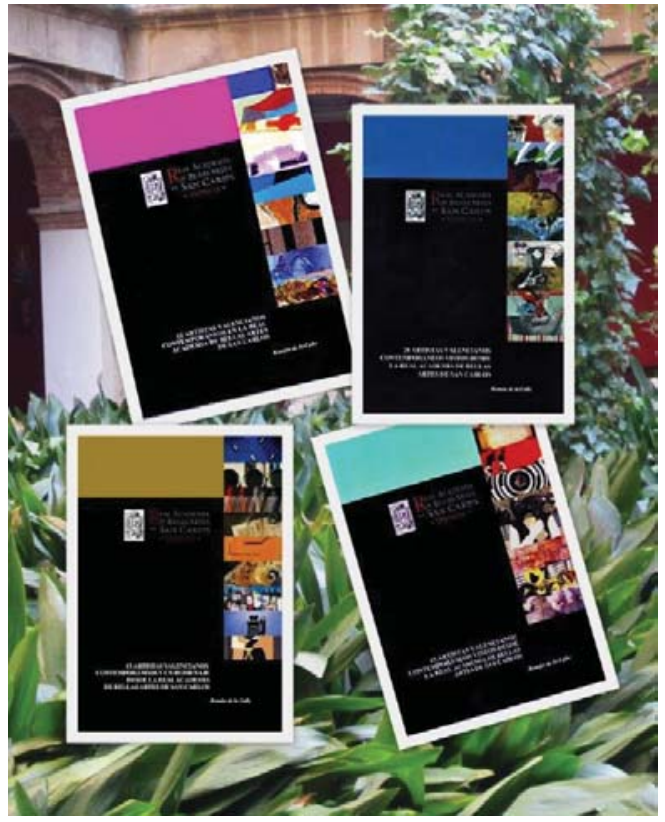

Figura 1. Ejemplares Real Academia

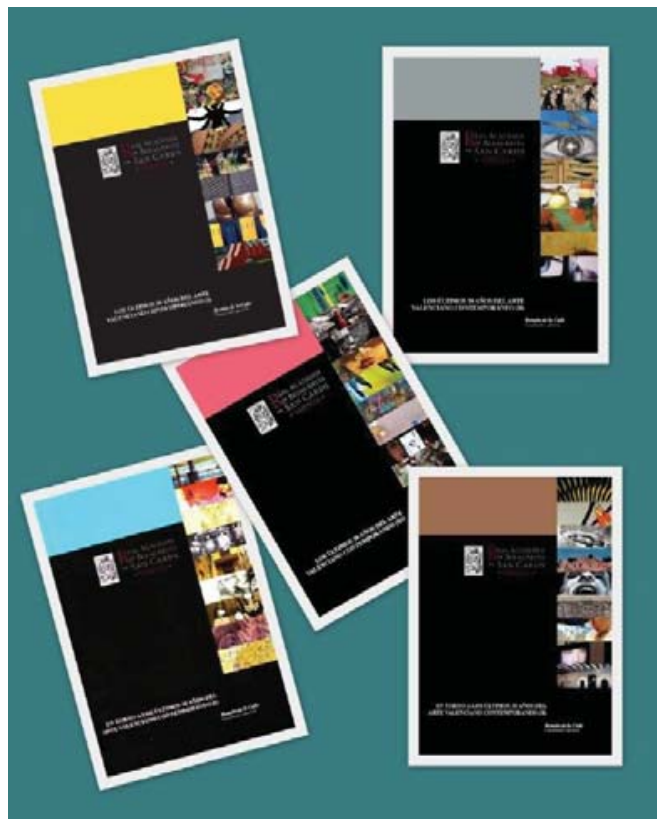

Figura 2. Ejemplares Real Academia

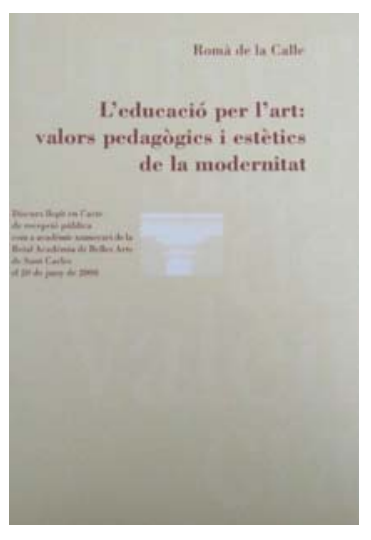

Figura 3. Portada libro L'educació per l'art: valors pedagògics i estètics de la modernitat
También quiero recordar que el tema de mi Discurso de ingreso en la Academia de Bellas Artes de San Carlos, después de mucho dar vueltas a la cuestión, fue L'Educació per l'Art: valors pedagògics i estètics de la Modernitat. Además, era la primera vez que se pronunciaba el discurso en valenciano y así se editó, en un volumen de 58 páginas, por el Servicio de Publicaciones de la Universitat de València (ISBN-84-370-4437-5). Quise realmente que ese título y su contenido fuesen, para mí, una especie de símbolo orientativo, de cara al futuro académico que, a manera de interrogante, pudiera aguardarme. 
Efectivamente, este periodo (2004-2007) fue francamente muy intenso para mí. Puntualizaré los motivos. Por una parte, por causa de la docencia universitaria, a la que siempre me entregué decidida y vocacionalmente y que no dejé. Han sido globalmente 43 años de profesor en tres universidades, conjugando docencia, investigación y gestión. Por otra parte, tenemos mi nombramiento como Director del Museo Valenciano de la Ilustración y de la Modernidad (MuVIM), (20042010), tarea a la que igualmente me dediqué, con sinceros afanes renovadores, en el marco de la museología, relativa al patrimonio inmaterial especialmente, con un equipo excelente de colaboradores y considero que con magníficos logros, como es notorio. También en el dominio de la Educación artística y la gestión de museos, campo en el que el convenio firmado con el Instituto de Creatividad fue decisivo, en cuanto a la realización de Jornadas y Congresos, a las numerosas experiencias en talleres educativos, investigaciones diversas y publicaciones. Asimismo, en tercer lugar, llegaba de pronto mi nuevo compromiso con la Real Academia. Tres flancos, pues, que debí alternar, según los períodos respectivos, por lógica incompatibilidad, en ciertos casos. De hecho, la Real Academia ha funcionado de equilibradora charnela, durante años, entre las otras diferentes tareas profesionales, es decir entre la universidad, el mundo de la educación y el ámbito de la museología. En realidad, no ha sido fácil mantener este intenso esfuerzo de dedicación, llevado a cabo como a tres o cuatro bandas.

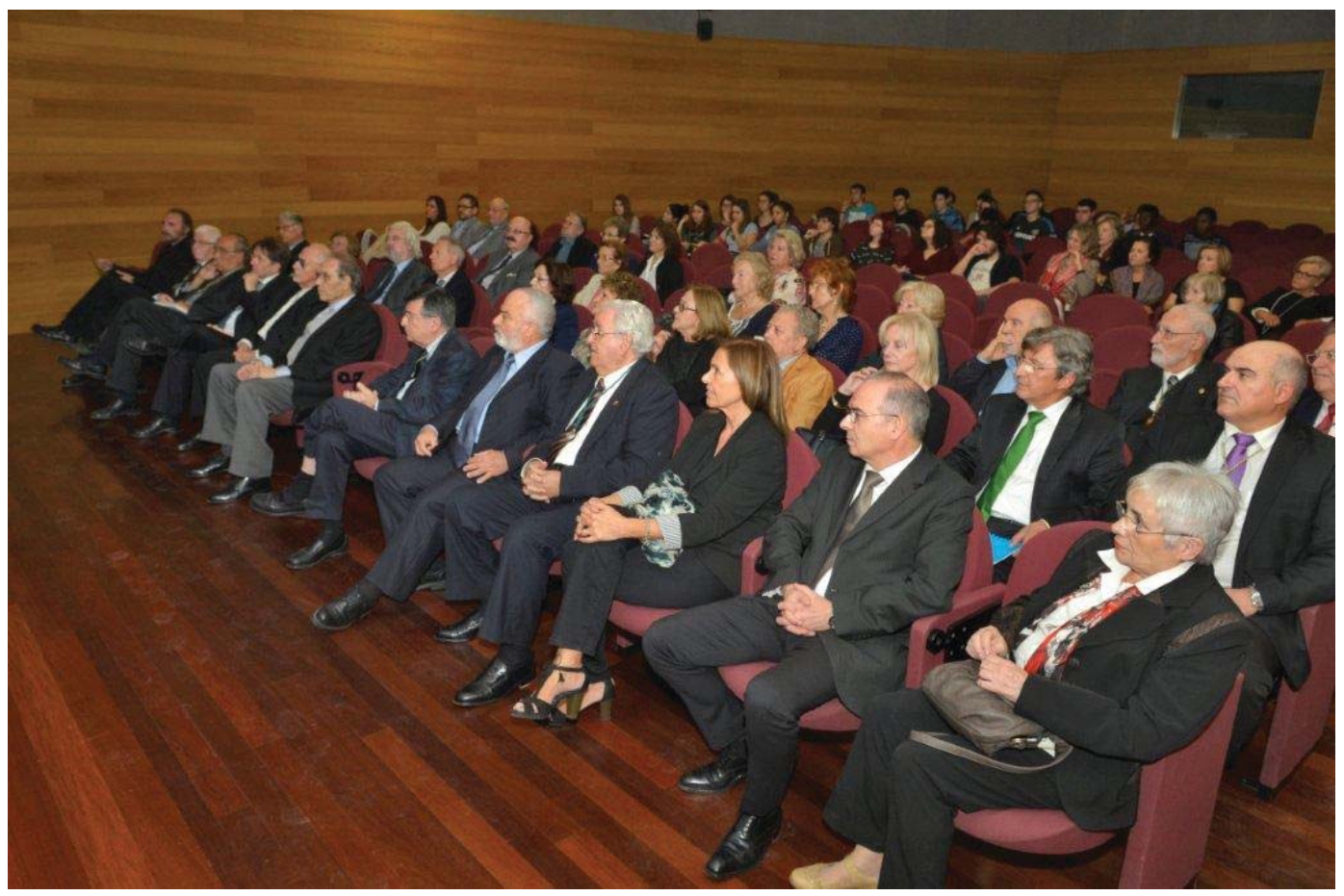

Figura 4. Miembros Real Academia 


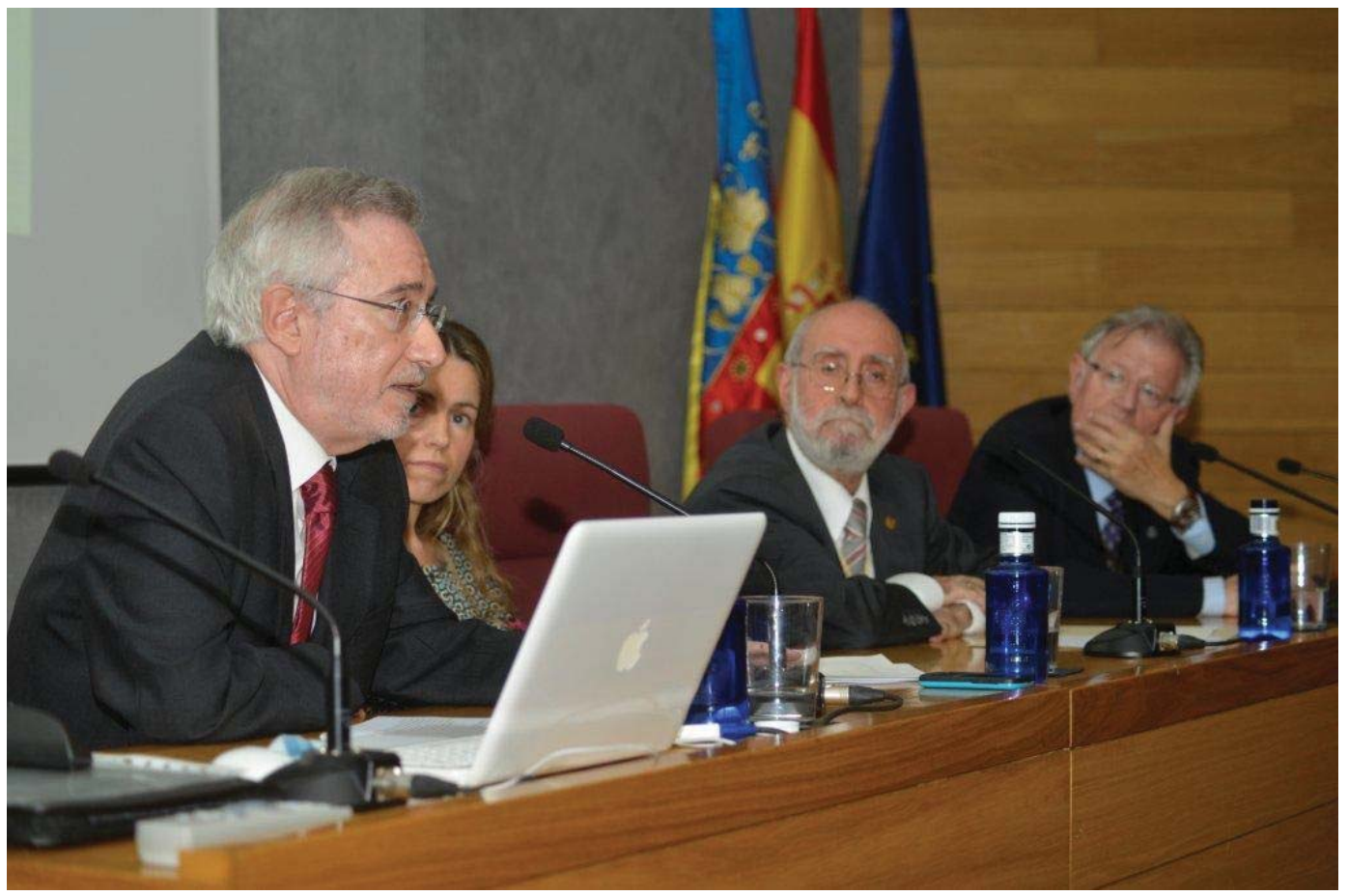

Figura 5. Apertura curso Real Academia

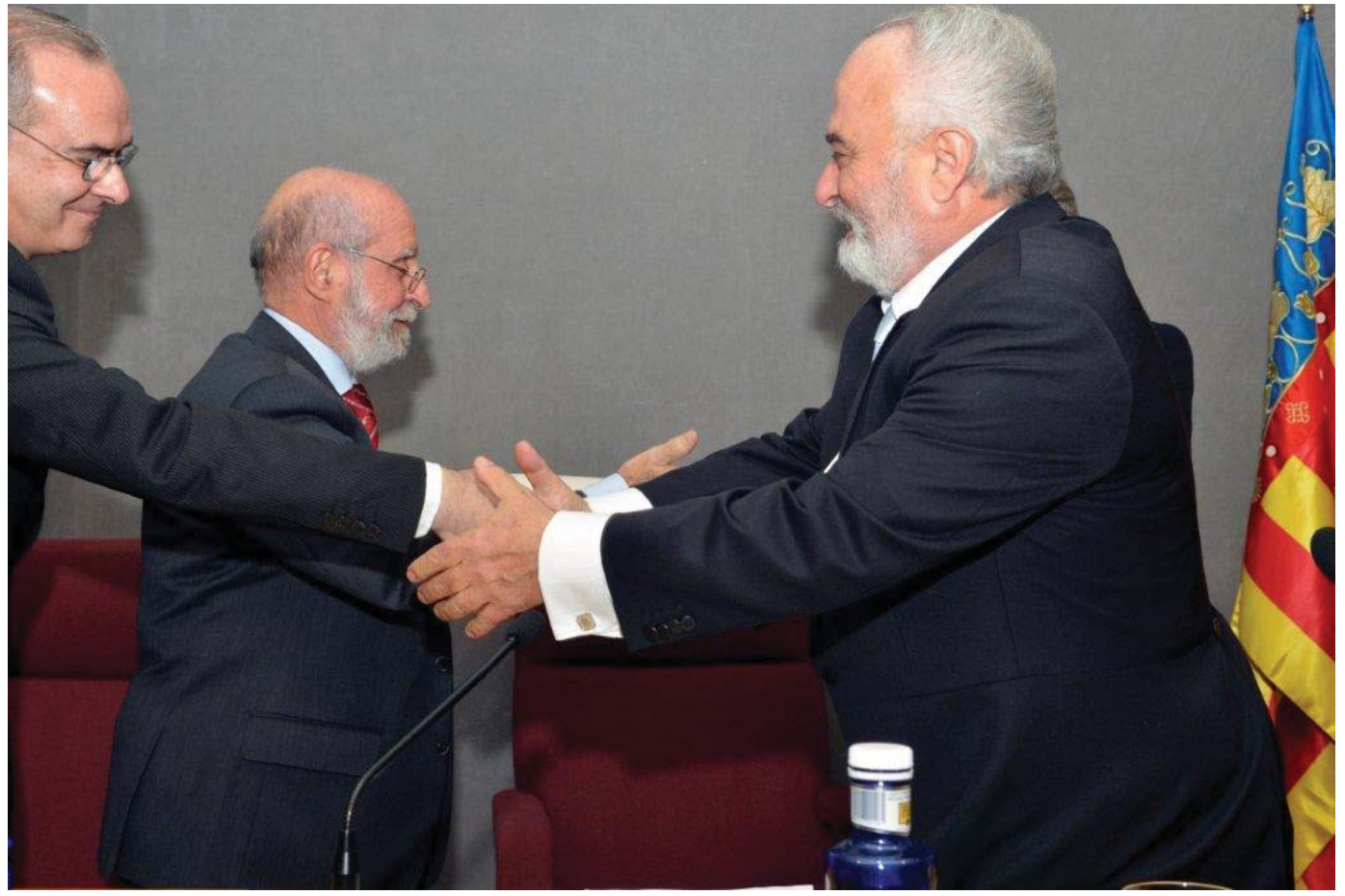

Figura 6. Recepción académico 
Quiero pensar - considerándolo ahora, en perspectiva-- que sin la experiencia adquirida como Vicepresidente de la Real Academia de San Carlos, en el periodo del profesor Joaquín Michavila, pintor y pedagogo, ciertamente no hubiera pasado por mi mente, luego, hacerme cargo de la Presidencia de la Institución Académica. Pero la verdad es que en diciembre del 2006, por motivos que no vienen al caso, presenta su dimisión el profesor Joaquín Michavila y renuncia a la Presidencia y consecuentemente debo asumir, de manera imprevista, la responsabilidad de dirigir, en funciones, la entidad. Así me sorprende el azar de la historia, estando aún dirigiendo el MuVIM, con máxima intensidad y dedicación. Sin duda, la coyuntura merecía una profunda reflexión y la sostuve responsablemente.

Es sabido que los académicos no perciben, por serlo ni por las tareas desempeñadas, remuneración económica alguna. No sucede igual, que digamos, en otras instituciones, con perfiles sumamente semejantes, de nuestro propio entorno valenciano. De ahí que la decisión, por parte de los académicos, de asumir tales responsabilidades siempre vaya unida a la generosidad, a la dedicación y entrega, nunca exentas, además, de cierto grado de sostenida utopía. Según los Estatutos y el Reglamento institucionales, la ocupación titular de la Presidencia puede repetirse en tres mandatos cuatrienales, por votación -para el acceso-- de sus miembros numerarios. La verdad es que siempre me pareció excesiva (12 años) tal posibilidad de duración cronológica. De hecho, en el 2007, contando con una sólida candidatura a mi lado, conformada por seis personas preparadas, asumí el mandato (20072011), que sería asimismo renovado otra vez (2011-2015) unánimemente. Han sido ocho años, pues, que cronológicamente han venido a coincidir con los peores años de la crisis socioeconómica y moral que nuestro país ha sufrido. Lo cual ha tenido ciertamente, como puede ser imaginado unas consecuencias de dificultad, restricción y tensiones excesivas, que no dejaron de problematizar, en demasía, institucional y personalmente-- nuestros objetivos y funciones.

\section{¿Podría hacernos, en líneas generales, un balance global de su gestión?}

Tuve claro, desde el principio, que la historia de la Real Academia, a punto de cumplir ya los 250 años de existencia, siempre estuvo alimentada por su directa vinculación con la docencia -es decir, con la Educación Artística-- a través de la creación y sostenimiento, desde sus orígenes, de la Escuela Superior de Bellas Artes de San Carlos, y con el Museo de Bellas Artes, a ella ligado, desde un siglo después, donde vinieron a confluir sus afanes patrimoniales y de conservación, sus ideales de divulgación pedagógica, catalogación y archivo. Escuela y Museo fueron, pues, los dos ejes y los dos objetivos, en torno a los cuáles se gestó y desarrolló, diacrónicamente, nuestra institución académica, en su dilatada existencia. Primero como Academia de Santa Bárbara y luego como San Carlos: apasionantes zigzagueos de la historia. 
Nacida oficialmente en 1768, acogida en una parte del edificio histórico de la Universitat de València, allí convivió casi un siglo, concretamente hasta la desamortización del Convento del Carmen, donde, de nuevo, a lo largo de casi otro siglo, atendió a la docencia de la Escuela y a la consolidación del Museo, siendo, por ello, los Presidentes de la Academia, a la vez, responsables y directores tanto de la Escuela como del Museo, hasta que en los años 40 del siglo XX, Academia y Museo pasaron simultáneamente al edificio que aún hoy comparten y ahora -por fin-- se rehabilita: el San Pio V. Mientras que, por su parte, la Escuela Superior de Bellas Artes permanecería aún algunas décadas en el Convento del Carmen, hasta convertirse en Facultad e incorporarse a la Universidad Politécnica de Valencia, ya en el último tercio del siglo XX.
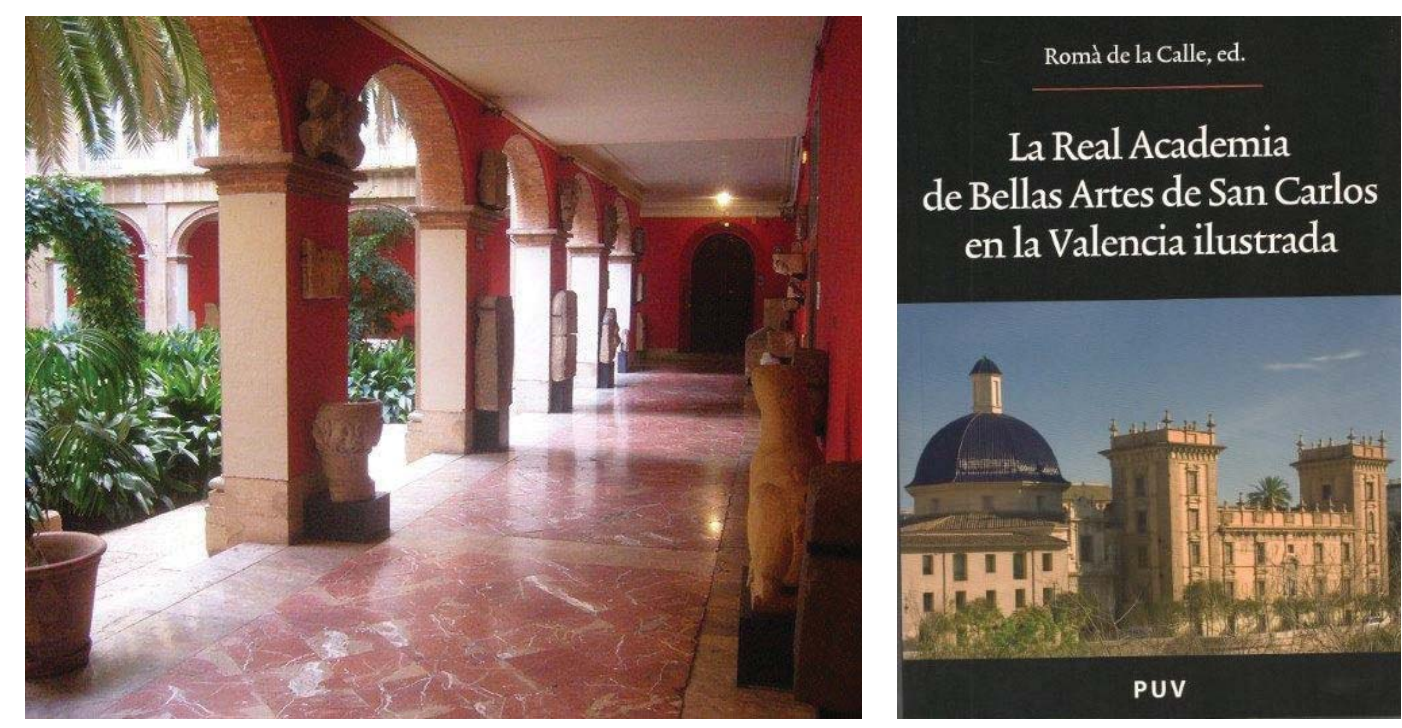

Figura 7. Claustro Real Academia

Figura 8. Portada libro Real Academia

Ahora bien, la historia hizo que la intervención de la política estatal replanteara simultánea y doblemente la trayectoria de siglos de nuestra institución académica, así como también sus funciones y sus objetivos. Fue un cambio sumamente drástico. Por un parte, la Escuela Superior de Bellas Artes pasó a depender del estado, por un decreto oficial y otro tanto sucedió con los distintos Museos de las Reales Academias, que pasaron, en general, a convertirse en Museos de Bellas Artes estatales, de carácter provincial.

Ambas decisiones intervencionistas del poder central mantuvieron activas, no obstante, las funciones de los Presidentes de la institución académica, que seguirían siendo --respectivamente y además-- Directores de la Escuela Superior y del Museo durante dilatado tiempo. El último eslabón personal de esta cadena, que mantuvo y retuvo sobre sí la presidencia académica y, a la vez, las direcciones, tanto del Museo de Bellas Artes como de la Escuela Superior, fue el Presidente número 53 de esta prolija historia, profesor D. Felipe Garín Ortiz de Taranco. Posteriormente la 
Escuela, como es sabido, ya devino Facultad de Bellas Artes, pasando a formar parte de la estructura universitaria y, por su parte, el Museo, tras el franquismo, en plena transición, recibió el nombramiento y designación de los primeros directores, ya desde la Generalitat y al margen, por completo, de la historia de la Real Academia. Fue una explícita decisión política, que las nuevas fuerzas gobernantes asumieron, de cara al futuro. Realmente, en aquellos tiempos de cambio y transición, quizás la Real Academia no pudo y/o no supo mover carta alguna en tal partida, limitándose a ser espectadora de cuanto sucedía en su entorno, con su carga histórica a las espaldas y escasos planes de futuro en su bagaje.

Estas puntualizaciones son, a mi modo de entender, fundamentales para poder conocer la coyuntura del replanteamiento funcional y teleológico, que, hasta la actualidad, ha debido asumir la institución académica, a través de la saga de sus presidentes posteriores: Prof. Salvador Aldana, Prof. Joaquín Michavila y Prof. Román de la Calle. Curiosamente, todos ellos - profesores / educadores de profesión (un historiador, un pintor y un filósofo), al margen de sus tareas académicas posteriores-- debieron reconocer y asumir que las funciones de dirección docente y de coordinación museográfica ya no contaban entre sus tareas, al menos mientras estuvieron directamente vinculados a la vida de la entidad académica.

Bien es cierto que patrimonialmente la Academia ha conservado la propiedad de sus amplios fondos artísticos (pinturas, esculturas, dibujos, grabados...) incrementados durante siglos, depositados actualmente en el Museo de Bellas Artes, de carácter estatal aunque de gestión autonómica, pues nunca fue cedida / transferida -en las negociaciones de la transición-- la titularidad del museo a la autonomía valenciana. Asimismo, el valioso Archivo Académico y sus muy notables Bibliotecas Histórica y Contemporánea constituyen los otros pilares básicos, fielmente conservados, de su existencia pasada y que exigen su continuada atención, incremento y puesta al servicio de los investigadores. Es, en efecto, la única manera de pensar activa y responsablemente en el pasado y en el futuro, sabiendo exactamente dónde nos encontramos y qué tenemos a nuestra disposición y al servicio de la sociedad.

Desde la barrera primero (como académico recién incorporado a la institución) y en pleno ruedo después, en cuanto Presidente, a menudo me he planteado y sometido a estudio la necesidad que la Real Academia tenía de clarificar, mantener y flexibilizar las relaciones con sus dos barandillas históricas: el Museo y la Facultad de Bellas Artes y generalizando aún más, con la universidad y con la sociedad circundante y con sus respectivas estructuras de poder, siempre a sabiendas, claro está, de defender a ultranza, en lo posible, su arriesgada autonomía.

A menudo, me he sentido un solitario funámbulo, desplazándome en altura, conocedor de que el balancín que mantenía en mis manos era, ni más ni menos, el híbrido resultado de una historia fecunda y de una movediza actualidad. Me explico. Dejada caer, por decreto, la dedicación a la museología y traspasada la tarea docente 
de las bellas artes a la universidad, la Real Academia ha mantenido aún en su poder algunas cartas determinantes, de cara al cumplimiento de sus compromisos actuales: a) ahí está la amplia función asesora y consultora, vinculada en continuidad con el pasado y activada sostenidamente en el presente institucional; b) no debe relegarse tampoco la tarea de investigación y de edición, a ella conectada, como generación y transmisión de conocimiento, referidos, por definición prioritaria, al arte valenciano y, por extensión, a sus conexiones sociohistóricas globales; c) nunca hemos olvidado las actividades educativas, de extensión cultural, de diálogos interdisciplinares, de cohesión e integración social que, a través del cultivo y el estudio de las artes, la Real Academia ha venido fomentando y haciendo imprescindiblemente suya, a menudo con la colaboración y a través de los convenios firmados diligentemente con otras entidades.

Considero que el balance que --por mi parte y durante los dos mandatos que he cumplido, junto al equipo de la Junta de Gobierno-- en torno a estos tres ejes citados, cabe efectuar, puede considerarse francamente positivo, en la medida en que hemos hecho lo posible, en diferentes escenarios, por dejar el listón lo suficiente alto, en el periodo (2007-2015), siempre contando con los efectivos aportes y respaldos incondicionales de la mayoría de los miembros académicos.

\section{¿Cómo queda la Real Academia y en qué situación se encuentra, en el momento actual de su marcha, como el Presidente $n^{0} 55$ de su ilustrada historia?}

Pasando a aspectos más concretos, comenzaré apuntando la situación de ilusionada expectativa que las obras del edificio del San Pio representan para el futuro de la institución, tras lustros y décadas de sobrevivir en circunstancias límite, sobre todo por el deteriorado estado histórico de la zona académica en la que se ha mantenido / resistido la ocupación. La verdad es que he soñado muchas veces en la adecuada instalación de nuestros archivos y de nuestra biblioteca, en espacios idóneos para los investigadores, colaboradores y académicos. Cuantas películas kafkianas se hubieran podido filmar in situ, durante lustros de penuria.

Junto a la relevante cuestión de los espacios está asimismo el tema de los medios, de los recursos. Tras el convenio firmado con la Generalitat, por el que hace décadas, se oficializaba el depósito de nuestro patrimonio artístico en el Museo --manteniendo siempre la propiedad, por nuestra parte-- también se reconocía, a la vez, a la Real Academia como histórica entidad consultora y además una representación de la misma entraba a formar parte del Patronato del Museo de Bellas Artes (integrado a tres bandas por el Ministerio de Cultura, por la Generalitat y la Real Academia, junto a la dirección del Museo), pensamos que, en cierta medida, se había normalizado nuestra existencia académica. Pero no fue así. Y el mejor ejemplo de lo dicho puede tomarse de mi experiencia como Presidente en estos ocho años, coincidentes 
con la crisis. En el reciente balance de la entrega de cuentas al nuevo equipo de Presidencia, hace tan sólo unos días, el gráfico explicativo presentado, por mí, a la Junta General, referente a la última década, es ya de por sí sumamente elocuente: un cuadro estadístico cuyo gráfico descendente cruza, de extremo a extremo el rectángulo, como irregular bisectriz, representando así elocuentemente la restrictiva historia económica de nuestra institución. Se muestra así, didácticamente, el límite de la reducción paulatina, a sólo un séptimo (sic), el conjunto de los ingresos reales del periodo. Hay que tener sumamente claro que estamos hablando no de una subvención otorgada sino de un convenio que obliga, con su firma conjunta. Y puedo afirmar que la Academia ha cumplido, por su parte, escrupulosamente, siempre, sus cláusulas: en realidad, no ha retirado ninguna de las obras depositadas en el museo, por ejemplo. Al contrario, las ha incrementado ampliamente. Y sin embargo los recortes y restricciones han funcionado, por lo general, más como un versátil castigo, aleatoriamente aplicado desde el poder y su representación personal, que como un respaldo institucional efectivo. Doy fe, insisto, de ello. Una experiencia, pues, para no olvidar. Ciertamente, la Administración ha sabido gestionar estratégicamente su maltrato, sobre todo entre los años 2008 y 2012, frente a nuestra histórica entidad.

La Academia queda ahora, por tanto, supeditada principalmente -a día de hoy-a esperanzas y deseos de futuro más que a logros financieros efectivos. Se han retirado además, recientemente, también las ayudas del Ministerio (cuando se insiste, de forma descarada, en que "la recuperación ha venido para quedarse"); igualmente se perdió, de manera injustificada, la colaboración de la Diputación,

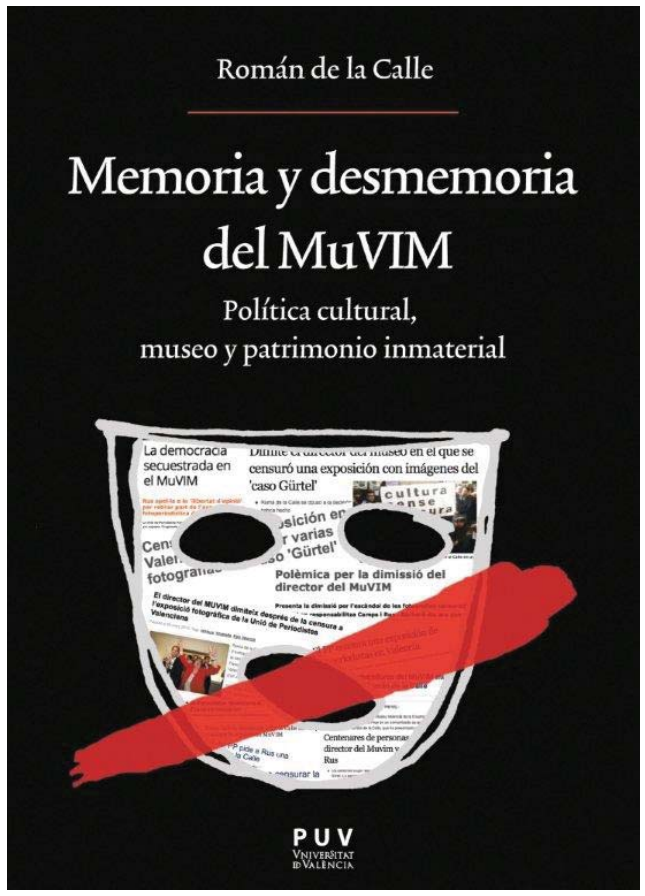

Figura 9. Portada libro Memoria y desmemoria del MuVIM hace unos años, muy significativamente para mí, como mensaje envenenado, tras mi polémico y testimonial alejamiento del MuVIM, cuando esa misma entidad, desde el siglo XIX, había mantenido, en continuidad, un explícito apoyo a la Academia. Piénsese en los Pensionados y en los Premios que históricamente la Diputación había propiciado y, de lo cual, sus colecciones de cuatros, de esculturas y grabados, de esas épocas, son el mejor espejo y testimonio. Igualmente y en simultaneidad, los respaldos de determinadas entidades bancarias, que habían sido asimismo persistentes, se retiraron con urgencia, por el foro de esa misma trágica escenografía. Mi memoria, en ese sentido, está plagada de duros recuerdos, pero también de inesperadas excepciones y respaldos. 
Por fortuna no han faltado, al hilo de la gestión de nuestro equipo, aportaciones de empresas, instituciones y destacados representantes, que han hecho posible, sobre todo, que -incluso en esta durísima coyuntura-- la investigación, las publicaciones, los premios de pintura otorgados y las actividades académicas, de cara a la sociedad, no hayan decrecido, sino que se han incrementado, programándose en nuestra Web, anualmente, con una puntualidad, interés y frecuencia, como nunca antes había sucedido. La imaginación al poder. Algo nos ha quedado aún vivo de aquel generacional espíritu sesentaiochista, que -al menos, por edad-- nos acompaña.

Respecto a la estructura del personal colaborador con el que contaba la Real Academia, para mantener el Archivo y la Biblioteca académica y atender a los investigadores y sus consultas, así como para el servicio documental institucional del funcionamiento de la entidad, en sus diferentes vertientes, hay que confesar que la curva numérica descendente, que representa al personal asignado a la entidad, ha seguido temporalmente la misma inclinación que la gráfica económica ya comentada. De hecho, según se han ido jubilando los funcionarios que teníamos asignados, desde décadas, se han amortizado sus plazas, con el puntual visto bueno de la Generalitat, paso a paso y sin excepción. En la actualidad, mantenemos --por contratación-- a nuestros dos colaboradores, a expensas del estricto presupuesto académico, habiéndose retirado todo tipo de apoyo, en lo que se refiere a la cuestión del personal, que había permanecido vigente durante medio siglo, teniendo en cuenta el servicio social y patrimonial, a demás de totalmente gratuito, prestado por la Academia.

\section{¿De qué se siente más satisfecho, en esta coyuntura?}

Sin duda, por una parte, se ha consolidado la presencia activa de la Real Academia, en colaboración con las universidades, en lo que respecta a la investigación en torno al arte y las publicaciones correspondientes. Ya he expuesto, antes, mis prioridades respecto a las funciones y objetivos académicos en la actualidad. Pero deseo insistir en esta vertiente de creación y transferencia de conocimiento como palanca educativa y social. Por ejemplo, justo en este año 2015 se cumple el centenario de nuestra revista Archivo de Arte Valenciano. Pocas revistas culturales cumplen cien años, en tan buena salud.

Fue en 1915, cuando la Academia decide publicar su revista de investigación, vinculada al arte valenciano, como su título consagra. Las generaciones han mantenido activo este proyecto institucional, convertido en hilo conductor de nuestra historia. Pues bien, en el año 2007, al asumir la Presidencia me planteé la necesidad de rediseñar y redefinir nuestra revista. $Y$ así lo hicimos con la complicidad creativa de Paco Bascuñán. Considero que la publicación, en estos años, se ha transformado y convertido en una de las más destacadas de nuestro contexto nacional, con un consolidado prestigio, de cara a la excelencia exigida en el marco universitario. Asimismo "Archivo de Arte Valenciano", como publicación repristinada, se ha 
visto acompañada por el Anuario Académico, un volumen -pensado como un cuaderno manual-- especializado en la vida y actividades académicas, que ya ha cumplido ocho años, diferenciado en funciones y objetivos de la propia revista. Sin duda, ambas publicaciones son la admiración de otras instituciones académicas. Y tal era uno de nuestros proyectos, junto a la creación también de una colección de libros, por parte de la Academia, que titulamos "Investigacions \& Documents", para recoger en ella los resultados de los trabajos y las colaboraciones en el campo de la investigación. De hecho, los números de la colección publicados han alcanzado ya los 22 volúmenes. Éste es otro de los logros destacados, que será difícil sobrepasar en eficacia y rendimiento.

En este marco de edición, destacan, por cierto, determinados proyectos: (a) La enciclopedia colectiva, en 5 volúmenes, titulada "Los últimos 30 años del arte valenciano contemporáneo", en la que han colaborado nada menos que 52 especialistas, a partir de un Proyecto I $+\mathrm{D}+\mathrm{i}$, concedido por el Ministerio de Ciencia y Tecnología, el respaldo imprescindible de ambas universidades públicas de Valencia y también la ayuda sostenida de Ámbito Cultural. No dejo aún de sorprenderme de este trabajo colectivo, coordinado desde la Presidencia de la Academia, durante seis años de esfuerzo ejemplar. ¿Cómo no voy a sentirme orgulloso de este respaldo colectivo? (b) También otros proyectos de investigación y edición han sido los realizados en colaboración con la Facultad de Bellas Artes. Que la Real Academia y la Facultad caminaran próximas en la historia actual, era una meta insoslayable y fácilmente comprensible, desde mi punto de actuación. Las relaciones Museo / Academia y Academia / Facultad de Bellas Artes significaban una exigencia heredada que he deseado cumplir, incluso con persistente generosidad. Por eso quiero recordar el proyecto titulado “¿Cómo investigar en las Bellas Artes?”, que ya se ha materializado en dos volúmenes: "¿Cómo investigar en los dominios de la música?” y “¿Cómo investigar en artes plásticas?”, estando también en proceso iniciado el tercer escalón: “CCómo investigar en el ámbito del Diseño?”. Y así podríamos referirnos igualmente (c) al proyecto personal que ha conseguido reunir, en 4 volúmenes, 60 estudios sobre "Artistas Valencianos Contemporáneos, vistos desde la Real Academia".

Nunca antes la vida de la Academia había afrontado tales retos de investigación. Y así desearía que continuara la institución en el futuro, en esta vertiente editora, haciendo historia. Pero la historia se hace y construye cada día. Por eso, parte de nuestro trabajo es estudiar, seguir e interpretar nuestro entorno actual, también nuestro arte contemporáneo vivo. La Academia --para conducir y conducirse por las autopistas, los caminos, atajos y veredas de la historia-- debe saber mirar por el espejo retrovisor, es claro, pero también resueltamente por el parabrisas. Y justamente el mejor termómetro de su comportamiento, en tal sentido, puede descubrirse y medirse a través de los contenidos de sus publicaciones. He ahí una buena pista de su deambular creativo: hacia dónde, cómo, cuanto y por qué. Esas son preguntas y cuestiones básicamente educativas que la Academia nunca debería 
olvidar. La llave de la vida académica siempre fue su interés por el presente continuo de los momentos paralelos de su existencia y, para ello, el bagaje del pasado, convertido en experiencia heredada, es y será imprescindible instrumentalmente, pero manteniendo los pies en el seguimiento y participación que apuntan hacia la exigente, compleja, apasionante y difícil actualidad.

Respecto al patrimonio académico, se ha atendido muy especialmente a la conservación y protección de nuestros Archivos, invirtiendo en las armariadas de madera, que actualmente conforman una escenografía nunca antes pensada, con un esfuerzo inversor destacado, superando la imagen de las cajas de cartón acumuladas por doquier, en otros momentos. Igualmente, respecto al incremento de la Biblioteca histórica, quiero recordar las inversiones, con salida a subasta internacional, para completar, por ejemplo, libros del XVIII, antes del endurecimiento de la crisis económica. Gracias a cuya gestión se incorporaron numerosos textos históricos a nuestro fondo bibliográfico, uno de los ciertamente interesantes y valiosos de la ciudad. Asimismo, hemos activado, en estos dos mandatos presidenciales, contando con la generosidad de muchos académicos y otros artistas, la complementación de la colección de dibujos de la Real Academia, que se había quedado en la charnela de la transición política española y, que de este modo, ha ampliado sus fondos y se acerca también a la actualidad artística. Ya me gustaría que el nuevo equipo no relegara estas funciones, lentas, esforzadas, nada fáciles y a veces casi invisibles, pero imprescindibles, de cara al enriquecimiento paulatino de los fondos artísticos de nuestra historia.

Tampoco debe silenciarse el incremento de la colección de pintura contemporánea de la Academia, depositada preceptivamente en el Museo, gracias el anual "Premio Nacional de Pintura Real Academia de Bellas Artes de San Carlos", que ya ha llegado a su XVI convocatoria. Ha sido esta aventura sorprendente fruto de la ejemplar colaboración entre la Academia y Ámbito Cultural. El Corte Inglés, en estos años de dificultades, se ha convertido en una palanca imprescindible, en tres vertientes destacadas: en los Premios de Pintura ya citados, que han incorporado más de 30 obras de pintura a nuestros fondos; en los Ciclos de Conferencias que, bajo mi coordinación, se han llevado a cabo en estos ocho años, siempre impartidos por especialistas y financiados por Ámbito Cultural; en las actividades expositivas, promocionando valores emergentes, que por convenio entre la Academia, el Centro de Documentación de Arte Valenciano, adscrito al Institut de Creativitat de la Universitat de València y Ámbito Cultural (en sus espacios expositivos) ha permanecido activo ya durante 6 años, desarrollando una tarea loable en la promoción y respaldo del arte joven. De alguna manera, la Academia, al carecer de espacios expositivos propios, ha debido poner a volar su imaginación, con tal fin. Ciertamente aventuras e ilusiones no nos han faltado, al menos en este período, directamente preocupado por el contexto de la actualidad. 


\section{¿Cree que su trabajo ha sido lo suficientemente valorado, en el contexto social, frente a otras instituciones?}

Siempre he pensado que no y además he tenido la impresión de remar a menudo, contracorriente, aunque jamás me faltaron los ánimos. Unas veces, porque la propia independencia, convincentemente defendida, conlleva la presencia de fuertes contrapesos. Otras, porque el propio contexto institucional, en el que inevitablemente nos movemos, convertido en balanza inestable, al respaldar desde la Generalitat, con prioridad al brazo museístico, silenciaba paralelamente al copresente brazo académico. Así ha sido y ha actuado el espacio escenográfico del poder cultural en nuestro contexto valenciano, desde que, de alguna manera, en el inicio mismo de la transición, se dio por supuesto que los responsables del museo, por definición --cargo y aspiraciones sobrevenidas-- tenían como misión explícita o secreta mantenerse como contrapeso evidente de la Academia. Tal sensación y experiencias son y han sido compartidas por muchos participantes en esa citada escena, en torno a San Carlos. De hecho, una de mis promesas proyectadas fue plantearme estratégicamente la normalización cotidiana entre la dirección del Museo y la Presidencia. Quizás mi talante dialogante ha podido significar determinados logros en el día a día de nuestra presencia en el Patronato del Museo, aunque siempre con explícitas y claras limitaciones.

Por ejemplo, el hecho de que nuestras obras de arte y también los documentos de catalogación y archivo referidos a las mismas, pasaran a conservarse en el museo cuando -por decreto oficial-- se convirtió en Museo Provincial de Bellas Artes, escindiéndose de la dirección académica, ha dado pie a frecuentes y reiteradas tensiones, al no conservar ya la Academia las obras pero tampoco los documentos históricos de catalogación, ni las copias de listados y referencias que se iban completando en los paulatinos estudios de los conservadores. Bien es cierto que personalmente, siempre que he necesitado consultar o investigar en torno a nuestras obras, depositadas en el museo, he podido hacerlo. Pero, también es cierto, que a día de hoy, en este tramo de años de la transición, nunca hemos dispuesto de una copia catalográfica, oficial y actualizada, de nuestras obras (grabados, dibujos, pinturas, esculturas y demás fondo patrimonial). Ya me gustaría que, en nuestra Web, fuera accesible también esta riqueza informativa, de manera general y que no se ciñera el acceso, restrictivamente, sólo a la siempre encomiable tarea de los investigadores, que acuden a su consulta profesionalmente.

La palanca de la visibilidad / invisibilidad de la institución se halla, en cierta manera, sometida, efectivamente, a estas enigmáticas historias cruzadas, que los diferentes presidentes, desde Felipe Garín Ortiz de Taranco, hemos vivido y revivido, transgeneracionalmente, compartiendo edificio y problemas, a menudo ilógicos en sus internas radicalidades. 
Insistiendo en la valoración externa de los esfuerzos llevados a cabo, en ese sentido, he de confesar que nunca me ha desvelado en exceso tal limitación, históricamente arrastrada. He preferido centrar mis energías en hacer cosas y en colaborar en proyectos interdisciplinares, que en conspirar extrañamente, frente a posturas enigmáticas. Y si ha habido que reaccionar, en algún sentido concreto, lo he hecho cuando ha sido necesario.

Considero, respondiendo a la pregunta, que el entorno especializado y el marco ciudadano, involucrado en la cultura, sí que ha podido apercibirse de ciertos cambios y del sostenimiento mantenido desde la Real Academia, en este periodo. Ciertamente, el no tener ni disponer de espacios expositivos propios es otro hándicap indiscutible para nuestra visibilidad institucional. Pero hay lo que hay y tenemos lo que tenemos, aunque quizás hemos debido preocuparnos históricamente mucho más, acerca de estas cuestiones sobrevenidas. ¿Por qué en 250 años ninguno de los 54 presidentes que me han precedido, pensó jamás en lograr espacios propios para la Academia, debidamente documentada su cesión, sobre todo cuando hubieran podido fácilmente hacerlo? De hecho, ni se les ocurrió. No podían adivinar el futuro --en aquel transcurso de siglos y zigzagueos del poder-- como para imaginar lo importante que podría ser esta idea y esta posibilidad: tener espacios expositivos para mostrar nuestras obras. Ahí está la Real Academia de San Fernando como testimonio de lo que pudo y puede suponer esta opción, ahora comentada, y sus racimos de plurales consecuencias, para nuestra historia y también para el presente. Es posible que no hayamos sabido vender, comunicativamente, estas apuestas de futuro, en cada momento y que tampoco lo estemos haciendo ahora. Quizás mañana se nos recuerden determinadas cuestiones, desde la historia que se avecina.

\section{Uno de sus objetivos importantes ha sido, también, propiciar la renovación del entramado académico}

En efecto, siempre creí en la necesidad de llevar a cabo esa tarea y además en dos sentidos muy concretos: (a) por una parte, propiciando la propuesta a favor de la posible incorporación de académicos numerarios más jóvenes; (b) por otra, reforzando la creciente presencia de la mujer en el marco académico. En ambas vertientes considero que estos ocho años han marcado ejemplares derroteros, en su actividad, aunque, sin duda, quedan metas pendientes. Ahí están, por un lado, los nombres de Rafael Armengol, de Joan Cardells, de César Cano, de Bertomeu Jaume, José María Vives, de Paco Bascuñán (en su momento) o de José Saborit, mientras, que por otro, debo citar a Carmen Calvo, Amparo Carbonell, Pilar Roig, Ana María Sánchez, Antonia Mir o Aurora Valero, como actuales y recientes académicas.

Pero también pensé que la renovación de la vida académica debe materializarse en otros niveles, por ejemplo en mi propuesta de mantener activos y vigentes los Estatutos de la institución, pero sin dejar de reformar ampliamente el Reglamento interno. De hecho, esta propuesta no fue aceptada, en su día, cuando incluso ya 
tenía preparado un borrador de las reformas aconsejables, y considero que sigue siendo un caballo de batalla pendiente, que deberá recaer en el equipo siguiente. De hecho, las reformas no pueden dejarse en manos de la tradición y deben planificarse pensando directamente en el futuro. Considero que habría que revisar incluso las denominaciones de las Secciones en que se divide la Academia: ¿Por qué no adoptar, por ejemplo, "Arquitectura, Urbanismo y Paisaje" en vez de sólo "Arquitectura", por qué no "Música y Artes Escénicas" más allá del dominio estricto de la música, por qué no "Nuevos comportamientos artísticos" y "Arte y tecnología" para enriquecer el plano de la realidad actual, en los diálogos entre la imagen y la tridimensionalidad, a la vez que lográbamos, soto voce, que el Diseño se incorporase al dominio académico?

\section{¿Qué espera, de cara al futuro, del Museo de Bellas Artes, donde están depositados sus fondos patrimoniales académicos, tan notables y fundamentales, también para el propio museo?}

A las nunca del todo normalizadas relaciones pasadas y actuales, entre las dos instituciones, ya me he referido. Sin duda, la responsabilidad plena jamás es unilateral, pero ya recuerdo los consejos de mis predecesores en tal sentido, asegurándome los caballos de batalla sobre los que debería trotar constantemente y así ha sido. Pero más que de insistir en ello, deseo pensar --y así lo creo-- que sólo la aplicación efectiva --por parte de las autoridades políticas, responsables de la cultura valenciana-- de las Normas de Buenas Prácticas, nombrando, por concurso público y abierto, a los directores de los museos públicos, en un efecto dominó que siga los pasos del IVAM, podrán abrir la puerta a la efectiva colaboración entre la Academia y el Museo. Hace falta un diálogo profesional y directo entre los responsables de ambas instituciones, que sean capaces de caminar y construir juntos, en torno a una mesa común de proyectos, al margen de ruidos de sables políticos y/o intereses claramente sesgados. Si partimos de un mismo fondo de posibilidades institucionales y las metas se perfilan debidamente, de manera sostenible, apuesto a que las cosas pueden cambiar, en la medida en que las condiciones contextuales, sociopolíticamente, sean ya otras. Tal es mi apuesta. Tenemos, sin duda, unos y otros, mucho que ganar, pero más que perder, si las cosas no varían, a ese respecto. Y nunca, tanto como ahora, me ha parecido sentir un determinante aire fresco, próximo, soplando animadamente, desde el contexto social que vivimos, aunque no sé bien -por cierto-- si llegará de frente o nos alcanzará por la espalda. En esa escena de renovación, no dejo francamente de soñar. Vivimos un periodo enigmáticamente muy interesante y apasionado incluso. Por eso, a menudo, he apuntado que la Academia debería ampliar su acción socioartística y políticoeducativa, pasando de ser una entidad consultiva a convertirse en entidad interviniente, ampliando su radio de influencia, recorriendo el camino que va "del hecho de ser llamada al logro de hacerse oir". En tal contexto, a veces he tenido la triste sensación de que --entre nosotros-- política y cultura, a menudo, se transformaban en dos trenes muy diferentes, que-aunque discurriendo por carriles paralelos-- viajaban efectivamente 
siguiendo sentidos, intereses y objetivos distintos. Sin diálogo, solo con gestos intermitentes, para no chocar en exceso.

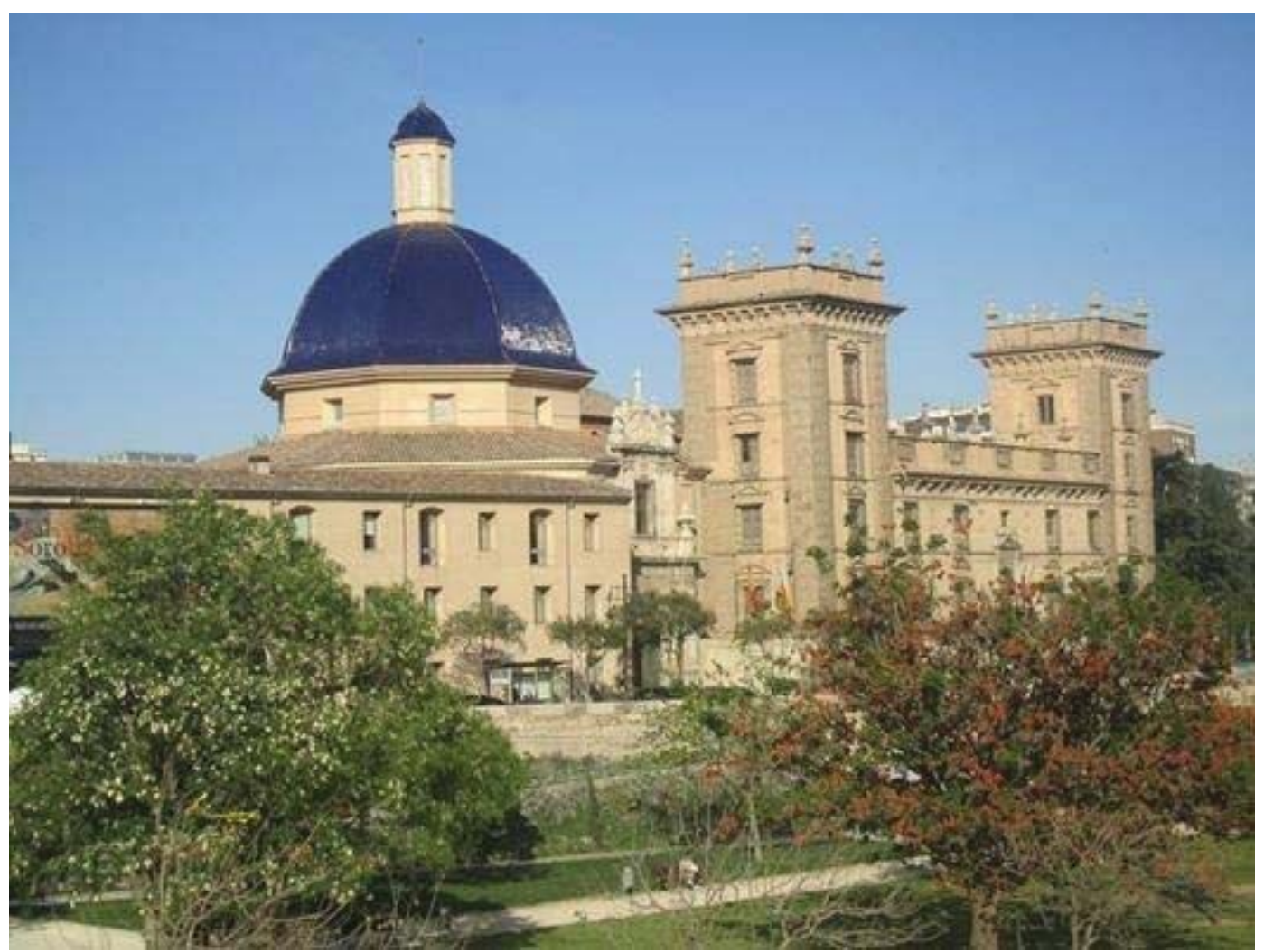

Figura 10. Museo y Academia

\section{Siempre ha estado relacionado profesionalmente con el tema de la educación artística. ¿Cómo, se ha referido a él, desde la Real Academia?}

Efectivamente, la Real Academia nació en el XVIII vinculada al tema de la docencia en torno al arte. Se trataba de formar profesionalmente a los futuros artistas, mediante la creación de la Escuela de Bellas Artes y además de educar el gusto de la sociedad. Ideales ilustrados que fueron su punto de partida. La misma preocupación por la formación de un museo conectado a la Academia nació de ese mismo rescoldo pedagógico. Y así ocurrió con Artes y Oficios y con la Escuela Superior a lo largo de los siglos. Luego la independencia oficial de los estudios (Escuela de Artes y Superior de Diseño y Facultad de Bellas Artes, en este siglo) no ha restringido las buenas relaciones y colaboraciones entre nuestras instituciones. De hecho, si repensamos las funciones comentadas por parte de la Academia, podemos decir que son inseparables del tema general de la educación artística. Si decididamente, desde el Instituto de Creatividad e Innovaciones Educativas de la Universitat de València, hace más de quince años, pusimos en marcha el Postgrado de Educación 
Artística y Gestión de Museos, que aún sigue funcionando, hay que decir que la Real Academia e incluso el Museo de Bellas Artes siempre han estado colaborando en el proyecto. Efectivamente nuestras funciones nunca han estado ajenas a esa meta, entre didáctica y formativa. Las constantes actividades académicas, la investigación y edición antes comentadas, no hacen sino incrementar esas tareas y objetivos de educación social y personal de los ciudadanos, desde la vertiente artística, patrimonial y estética.

Incluso, la reciente creación de un galardón especializado anual, por parte de AVALEM (Asociación Valenciana de Educación Artística, Museos y Patrimonio) y el Institut Universitari de Creativitat que lleva el nombre de "Premi Romà de la Calle a l'impuls de la Educació Artística en Museus" ha sido, para mí una sorpresa y una alegría inexpresable -cuando el 27 de marzo 2015 fue entregado, en su primera edición, en el IVAM, a Emma Nardi, Presidente de CECA-ICOM-que viene a mostrar esa necesidad y exigencia social por activar esta vertiente de gestión cultural no siempre lo suficientemente respaldada. Justamente esa idea hace años surgió y fue propuesta a la Generalitat desde la Real Academia de Bellas Arres de San Carlos. Pero quedó archivada y ahora, felizmente, ha sido retomada desde otras instancias operativas. Pero, insisto, esa faceta educativa en torno al quehacer artístico ha sido y sigue siendo sustancial a nuestra institución, con su revista, sus colecciones de libros y su persistente actividad investigadora, de transmisión del conocimiento y formación del gusto. "Libertas artium restituta" era el lema ilustrado del movimiento académico y en esa brecha seguimos moviéndonos.

\section{¿Algún consejo a su sucesor?}

Nunca he sido excesivamente partidario de ejercer influencias a través de consejos. Ahora bien, es claro que cada nuevo equipo debe asumir su propio programa, sobre todo pensando en las limitaciones constatadas y en las posibilidades intuidas. No obstante, lo que siempre me ha parecido vergonzante, en las políticas culturales ejercitadas entre nosotros, ha sido llegar y destruir lo preexistente, por el simple hecho de la no coincidencia de intereses, de la variabilidad de prioridades o de ser ajeno a nuestro propio entorno personal. Y no creo que la sensatez de mis compañeros se aproxime a tal equívoco y peligroso barranco de comportamiento. La historia de nuestra Real Academia ha sido, más bien, una suma de aportaciones escalonadas y a ello me acojo, una vez más, en esta coyuntura. Nunca he pensado en posibles acciones de tierra quemada. Es más, incluso en el mismo día de las elecciones --cuando hacía meses que ya había comunicado mi no deseo de participar en un tercer mandato, aunque los Estatutos me lo permitían-- un grupo de colegas, públicamente, me pidió que continuase, hasta el 2019, y, por mi parte, ya insistí, de inmediato, en la conveniencia de que nuevos aires llegaran al contexto académico, en un esperado momento de cambios y adaptaciones. Nunca he querido quedarme pegado al viejo sillón de la Academia, ni a ningún otro. 
Ahora bien, en la medida en que conozco de donde salgo y lo que dejo detrás de mí, puedo comentar -y sólo en tal sentido-- que los espacios, tras las obras de rehabilitación actuales, a compartir entre Museo y Academia, por muchos estudios que se hayan hecho en estos años, siguen quizás siendo un secreto casus belli, que no deberá relegarse, en su importancia de cara al futuro. Me consta que a pesar de la famosa "Quinta fase" el museo seguirá deseando / necesitando nuevos espacios, quizás para convertirse realmente en el Segundo Museo Español, como tantas veces, dudosamente se ha afirmado y que la historia del arte valenciano merece. Claro que personalmente entiendo y comprendo tales limitaciones, a pesar de las mejoras derivadas de las obras tan deseadas. Pero antes de volver a hablar -- ¿para cuándo?-- de la "Sexta fase" preferiría apostar por el definitivo crecimiento del Museo de Bellas Artes (no a costa de la Academia) sino pensando en su ampliación hacia el vecino Convento de la Trinidad. Dos edificios para un museo. Podría ser algo semejante como la ampliación de El Prado. ¿Por qué no? Considero que ahí radica el verdadero secreto a voces del futuro de nuestro Museo Valenciano, por excelencia. Desde que lo soñé, hace años, una noche, no me lo he podido quitar ya de la cabeza, como si fuera una secreta misión pendiente. Por eso sigo esperando la posible llegada de unos políticos, capaces de apostar ciertamente por la cultura, por la educación, con visión de futuro, dejando a tras -de una vez-- este heredado erial actual, rodeado por doquier de historias de abusos, corrupción y deficientes opciones ejercitadas, que cada día siguen emergiendo y descubriéndose en nuestro entorno.

Espacios, pues, pendientes y también revisión, a tergo, de los convenios totalmente superados, transgredidos y olvidados, que se convirtieron en papel mojado, cuando políticamente convino, en paralelo a las experiencias de derroche sufridas, en determinados contextos. Se trata de pensar, de nuevo, en los medios pertinentes que la Academia necesita y merece. Tarea, pues, no le falta, mientras tanto, al nuevo equipo, de cara a dar más visibilidad a la entidad y a sus fondos patrimoniales, a su reubicación, a su economía, a sus actividades, investigaciones y esfuerzos editoriales. Que no se preocupe el nuevo equipo, ya que en estas históricas instituciones, siempre hay, afortunadamente, -aunque parezca lo contrario-- más futuro por materializar y construir que pasado por estudiar y difundir, aunque nos parezca, a los investigadores, patrimonialmente inagotable nuestra memoria socioartística compartida.

Valencia 26 marzo 2015. 